\title{
New proofs of some properties of essential submodules
}

\section{DANiela Adriana Heuberger}

\section{ABSTRACT.}

In 1986, Lambek [Lambek, J., Lectures on rings and modules, Chelsea Publishing Company New York, 1986] studied the connections between essential submodules and quotient rings, and in 2009, Steinberg [Steinberg, S. A., Lattice-ordered rings and modules, Springer New York Dordrecht Heidelberg London, 2009, 1-307] presented some interesting results in this field. The main aim of this paper is to provide proofs for those of these results for which we did not found old ones in the literature we studied, using the same techniques as in the mentioned books.
\end{abstract}

DePARTMENT OF MATHEMATICS AND COMPUTER SCIENCE

NORTH UNIVERSITY OF BAIA MARE

Victor BABES 62 / A 430083, BAIA MARE, ROMANIA

E-mail address: dana.heuberger@yahoo.com

Received: 30.10.2011; In revised form: 27.08.2012; Accepted: 15.10.2012

2010 Mathematics Subject Classification. 16D80, 16 S85.

Key words and phrases. Essential submodules, quotient rings. 